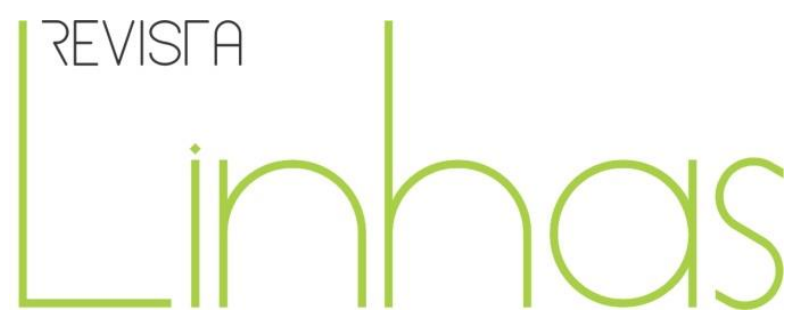

\title{
Semana Mariana do Colégio Juvenal de Carvalho: mito e rito na preservação dos valores socioculturais femininos
}

\begin{abstract}
Resumo
O artigo insere-se no campo da História da Educação, mais especificamente na história de instituições escolares. O objetivo da pesquisa foi compreender como o mito da mulher virtuosa, à luz do exemplo de Maria, transforma-se em rito na Semana Mariana do Colégio Juvenal de Carvalho para fomentar a educação feminina voltada para a preservação de valores morais que mantinham a mulher na esfera privada a serviço da família e do lar. Realizou-se uma pesquisa amparada teoricamente na história cultural, que adotou a história oral temática como metodologia. Utilizaram-se as narrativas orais de uma professora, irmã salesiana e do coordenador da Semana Mariana, coletadas por meio de entrevistas, como fonte de análise. Constatou-se que a Semana Mariana era um rito realizado, todo mês de maio, que, ao exaltar a figura de Maria como exemplo feminino a ser seguido, educava as moças para: a castidade, o casamento e a maternidade. Essa formação endossava o papel social atribuído à mulher de subserviência ao homem - pai e esposo - ao disciplinar seu comportamento para a obediência inconteste, restando-lhe, se não a vida religiosa, a união matrimonial com os afazeres domésticos e os cuidados com os filhos e com o esposo.
\end{abstract}

Palavras-chave: história de instituição; educação feminina; educação mariana; educação religiosa; Colégio Juvenal de Carvalho.
Vitória Chérida Costa Freire

Universidade Estadual do Ceará -

UECE - Fortaleza/CE - Brasil

vitoriacherida91@gmail.com

Lia Machado Fiuza Fialho

Universidade Estadual do Ceará -

UECE - Fortaleza/CE - Brasil

lia_fialho@yahoo.com.br

\section{Para citar este artigo:}

FREIRE, Vitória Chérida Costa; FIALHO, Lia Machado Fiuza. Semana Mariana Juvenal de Carvalho: mito e rito na preservação dos valores socioculturais femininos. Revista Linhas. Florianópolis, v. 22, n. 50, p. 293-319, set./dez. 2021. 


\title{
Semana Mariana Juvenal de Carvalho: myth and rite in for female socio- cultural values preservation
}

\begin{abstract}
The article is inserted in the field of the History of Education, more specifically in the history of school institutions. The objective was to understand how the virtuous woman myth, from the Mary example, becomes a rite in the Semana Mariana at Colégio Juvenal de Carvalho to promote female education. This education aimed the moral values preservation that kept women in the private sphere to the family and home service. The research methodology included a theoretical base on cultural history from a thematic oral history. Oral histories were collected through interviews. Interviews were conducted with a teacher, a salesian nun and the Semana Mariana coordinator. Results showed that Semana Mariana rite performed every May, exalting the Mary figure such as female example to be followed. The results revels that Semana Mariana rite educated the girls to: chastity, marriage and motherhood. This formation endorsed a social role woman: subservience to the man - father and husband -, disciplines woman's behavior for an unquestioned obedience, and a life dedicated to the religion or the marital union, the domestic tasks and the care for the child and husband.
\end{abstract}

Keywords: institution history; female education; marian education; religious education; Colégio Juvenal de Carvalho. 
A Ordem Salesiana é uma congregação da Igreja Católica que foi fundada no ano de 1859 e aprovada em 1874, em Turim, Itália. Almeida (2013) informa que a orientação de João Melchior Bosco, o Dom Bosco, inspirado no exemplo de vida de São Francisco Sales, considerado santo e doutor da Igreja, objetivava o desenvolvimento humano por intermédio do trabalho educativo pastoral.

Do contexto de industrialização na Europa emergiam os ideais de modernização e os aspectos de marginalização dos jovens ao longo do século XIX. Em meio a esse cenário, Dom Bosco formulou o Sistema Preventivo, que era uma proposta voltada para a melhoria da vida material, bem como educacional e espiritual do estudante salesiano (BORGES, 2000). A ênfase dessa pedagogia salesiana era o protagonismo juvenil, pelo qual Dom Bosco tornou-se o principal entusiasta responsável em elaborar práticas educativas para atrair e preparar os jovens com a mediação de músicas, jogos e atividades corporais.

Além das instituições destinadas à educação do público masculino, que inicialmente foi a prioridade de Dom Bosco, surgiram outros grupos que se vincularam à ordem salesiana na Itália: a Associação de Maria Auxiliadora, fundada em 1869 na cidade de Turim; o Instituto das Filhas de Maria Auxiliadora (de educação feminina), fundado em 1872 na cidade de Mornese; e a Associação dos Cooperadores Salesianos. Com o objetivo de expandir a ordem salesiana para outros países em conformidade com os propósitos da Igreja Católica, a ordem salesiana chega ao Brasil para implementar ações educativas no ano de 1883, a fim de apoiar a atuação dos bispos reformadores brasileiros (AZZI, 1982).

O Colégio Juvenal de Carvalho, localizado na cidade de Fortaleza, no Ceará, foi fundado em 1933, a partir da filantropia do Coronel Juvenal de Carvalho e entregue às Irmãs Salesianas. Sob orientação da Pedagogia de Dom Bosco e amparado na devoção à Nossa Senhora Auxiliadora, ele foi a primeira instituição educacional salesiana da cidade e obedeceu com rigor aos requisitos exigidos pelo Departamento Nacional de Educação quanto aos moldes nacionais de ensino, tornando-se pioneiro na equiparação oficial no Ceará para oferecer o Curso Secundário ao público feminino (MARTINS FILHO, 1966). 
A Semana Mariana, objeto deste estudo, consistia na realização de um ritual desenvolvido todos os meses de maio para exaltar a figura de Maria Auxiliadora como ideal de mulher que possuía princípios e virtudes que deveriam ser assimilados, por meio da pedagogia do exemplo, e postos em prática pelas alunas para a manutenção da ordem cristã e a garantia de um futuro venturoso.

O mote era tomar Maria como exemplo de mulher a ser seguido pelas crianças e moças matriculadas no Colégio Juvenal de Carvalho, ou seja, a prática pedagógica consistia em uma educação feminina voltada para formar corpos dóceis e obedientes (FOULCAULT, 2009), que, tementes a Deus, deveriam conduzir com maestria o papel de boas mães, esposas dedicadas, donas do lar, sempre dispostas a servir (SCOTT, 2012).

O problema central que estimulou o desenvolvimento da pesquisa foi: Como a Semana Mariana, realizada no Colégio Juvenal de Carvalho, era utilizada para a preservação de mitos e ritos que asseveravam padrões sociais e culturais que condicionaram a mulher à subserviência na sociedade fortalezense no início dos anos de 1990? A partir dessa inquietação, desenvolveu-se uma pesquisa científica com o objetivo de compreender como o mito da mulher virtuosa, à luz do exemplo de Maria, transformase em rito na Semana Mariana do Juvenal de Carvalho para fomentar educação feminina voltada para a preservação de valores morais que mantinham a mulher na esfera privada a serviço da família e do lar.

Parte-se do pressuposto de que a educação mariana, fomentada no Colégio Juvenal da Carvalho, e exaltada na Semana Mariana, endossava padrões socioculturais machistas e patriarcais que condicionavam a mulher à subordinação ao homem, ao asseverar a preservação de padrões comportamentais consoantes ao arquétipo de pureza, paciência e subserviência, que destinavam a mulher aos afazeres de dona de casa prendada, mãe e esposa dedicada.

Historicamente, a marca de submissão e exclusão da mulher perpassou não só a educação, mas todas as esferas da sociedade devido à forte superioridade atribuída culturalmente à figura masculina, que, consolidada pelo sistema patriarcal, negou direitos civis e sociais ao grupo feminino, como o acesso ao trabalho, o direito ao voto, a libertação sexual, o divórcio e o reconhecimento de identidades diversas (FIALHO; FREIRE, 2018; SCOTT, 2012). Com o incentivo da Igreja Católica e da sociedade civil, como 
infere Louro (2004), o perfil ideal de mulher era aquele que se dedicava a manter a subalternidade ao pai e ao marido, formar o matrimônio com a finalidade de procriação, ser obediente aos limites de acesso ao espaço público e manter a boa moralidade cristã e a higienização da sua família.

No Ceará republicano da década de 1990, meninas e moças de famílias abastadas tiveram acesso à educação formal a partir das instituições confessionais para a preservação da fé católica, a preparação para novos ideais de modernização e para formação no magistério, já que este espaço foi cedido ao grupo feminino por ser considerado uma extensão dos afazeres do lar e do cuidado maternal natural da mulher (ALMEIDA, 2012; RIBEIRO, 2000). O Colégio Juvenal de Carvalho foi um exemplo de lócus de formação feminina, respeitado pela elite cearense, que endossou a educação mariana, logo, compreender ritos que instituíam o lugar da mulher na sociedade possibilita não apenas compreender a história da educação, mas refletir criticamente o contexto que atrasou a participação feminina nos espaços públicos.

Os conceitos de mito e rito emergiram para ajudar a compreender as relações entre os ideais e as práticas do educar correlacionados aos valores sociais de uma época, no caso, os anos iniciais da década de 1990. O mito, como afirma Eliade (2007), é a narrativa de uma realidade do passado que perdura nos tempos como algo que foi produzido e retroalimentado pelos ritos materializando os mitos. Estudar a Semana Mariana do Colégio Juvenal de Carvalho é relevante para desvelar como os mitos, que relegavam o feminino a segundo plano de importância, perpassaram por muitas décadas nem sempre de maneira crítica e problematizadora.

Segundo Loriga (2011), estudos que reduzem a lente de análise possibilitam compreender realidades específicas com uma riqueza de detalhes e subjetividades não contempladas em pesquisas macrossociais. Inclusive, estas correspondem "a questões muito particulares e trabalha com o universo de significados, motivos, aspirações, crenças, valores e atitudes, que não podem ser reduzidos a operacionalização de variáveis" (MINAYO, 1994, p. 21). Dessa maneira, investiga-se a Semana Mariana Juvenal de Carvalho, e para isso consideram-se as narrativas de sujeitos que vivenciaram esse rito que fomentava a educação baseada na pedagogia de Dom Bosco, na devoção à Maria Auxiliadora e no desenvolvimento de práticas pedagógicas disciplinadoras. 
O artigo subdivide-se em cinco seções, a saber: “Introdução", que explanou a temática do estudo, sua delimitação temporal e espacial, o objeto de estudo, o problema de pesquisa, o objetivo, o pressuposto, as categorias centrais - rito e mito -, a relevância social do estudo, e a maneira de organização do texto; "Mito e rito, categorias conceituais elementares", que explicita o que se compreende por mito e rito nesse estudo, situando a Semana Mariana como um rito tradicional na educação salesiana; “Percurso teórico-metodológico da investigação”, que esclarece o percurso transcorrido para o desenvolvimento do estudo; "Semana Mariana Juvenal de Carvalho: educação feminina e valores marianos", que traz os resultados e as discussões da pesquisa ao explicar como se constituía essa celebração e os principais princípios morais que norteavam a educação mariana discutindo a maneira como esse rito apresentava o papel subserviente feminino na sociedade; e "Considerações finais", que retoma o problema e o objetivo da pesquisa para respondê-los sucintamente a partir da explanação dos principais resultados e discussões.

\section{Mito e rito, categorias conceituais elementares}

Muitas foram as tentativas teóricas levadas a efeito com o intuito de compreender o significado de mito, no entanto, não há uma única definição que possa dar conta da complexidade que envolve essa discussão (ELIADE, 1978). Enquanto desafio intelectual, ainda se apresenta como um fenômeno de apreensão difícil para aqueles que se dedicam a sua discussão, todavia, é possível visualizar algumas convergências conceituais que embasaram essa investigação.

Para Hobsbawm (1991), os ritos antigos são repetidos para legitimar práticas contemporâneas, logo, a invenção das tradições utiliza-se de práticas, ritos e símbolos regulados por normas aceitas socialmente, que elaboram uma relação com o passado perpetuando-se com o passar dos tempos. Essas tradições inventadas estabelecem uma falsa relação de continuidade em decorrência da repetição de um rito que já perdeu seu sentido original.

O mito é, portanto, uma forma de representação da realidade, da maneira de organização e sobrevivência humana em tempos anteriores, uma forma de preservar a 
cultura de seus antepassados. Os mitos estão relacionados à memória dos sujeitos e pela forma como são expressos para dar significado a explicações sobre origens, organização de instituições, manifestação e preservação de costumes (BARTHES, 2001).

Ante essa compreensão, o estudo em relato trabalha na perspectiva do mito como valor, imerso em um contexto de significação, ao buscar compreender a Semana Mariana como um mito que se reverberou na prática cotidiana, em âmbito educacional, em que nasceu e amparou-se nos ideais católicos e preservou-se pelo rito de manter o sexo feminino comportando-se à luz de Maria - ou seja, como mulher pura, imaculada, doce, paciente, virtuosa, temente a Deus, obediente e mãe dedicada (VASCONCELOS; FIALHO; MACHADO, 2018).

Para Eliade (1978), o mito pode ser definido como a narração de uma história verdadeira e sagrada sobre uma criação, que se torna válida e, por vezes, inquestionável. Nessa perspectiva, pode-se entender que o mito é uma forma de relatar acontecimentos na vida humana, ou seja, a sua origem, as suas ações diante da natureza, as suas atitudes na resolução de problemas do dia a dia. Segundo Scott (2012), as sucessões de aspectos do mito trazem um enfrentamento entre o abstrato e o real, o que gera o caos, que não significa simplesmente uma desordem ou um conflito, mas uma mistura necessária para sustentar os princípios e elementos do mito em sua representatividade, no caso, o papel destinado à mulher na sociedade brasileira.

À mulher, criada à luz e semelhança de Deus, a partir de uma costela de Adão, cabia não cair em pecado e não desobedecer ao homem. Este, mais sensato, racional e forte, era o provedor da ordem e da moral (RAGO, 1996). Esse mito colaborou para que a mulher, durante muitos anos, fosse destinada ao espaço privado, à subserviência ao sexo masculino - pai e marido - e à inferioridade física e psicológica (BUTLER, 1991).

A linguagem de cada mito varia de acordo com o espaço temporal em que ele é recontado ou reinventado, ou seja, são vários os rituais utilizados para endossar a preservação de mitos históricos (TAMANINI, 2010). Os rituais foram e continuam sendo uma forma de explicar determinadas posturas culturais e sociais e de preservar mitos, contudo, já não se concebe mais a assimilação acrítica dos conhecimentos passados de geração para geração (LANGDON, 2016), especialmente quando estes subjugam pessoas e as relegam a segundo plano de importância no contexto sócio-histórico. 
Sabe-se, todavia, que através dos mitos não apenas se explicaram problemas que o homem não conseguia responder, mas inculcaram-se crenças sociais e culturais com padrões que interessavam a determinados setores da sociedade - as elites financeiras, a raça branca, aos homens, aos eclesiásticos ${ }^{1}$ etc. -, para manutenção de um status quo favorável aos interesses de grupos específicos (HOBSBAWN, 1991).

A manutenção da crença em determinados mitos depende da prática de vários ritos, os quais consistem em preservar valores que foram constituídos como verdades (GUILOUSKI; COSTA, 2012), como é o exemplo da Semana Mariana do Colégio Juvenal de Carvalho, para preservar o lugar secundário da mulher na sociedade. Os ritos, enquanto conjunto de regras e paradigmas que caracterizam certa tradição, consistem numa repetição de atos definidos, elementos sistêmicos de alguma espécie de cerimônia, no caso, o culto a Maria todos os meses de maio, e reforçam valores a serem inculcados nas moças para a preservação do seu lugar social.

Os ritos mais comuns são os de passagem, ou seja, celebrações tradicionais que marcam mudanças de status de um indivíduo no seio de sua comunidade, no entanto, há tantos outros que colaboram para preservar padrões sociais, tais como: de batismos, de debutante $^{2}$, de casamentos, funerários, de sacrifício de animal, de formatura, dentre outros. Essas tradições, muitas vezes relacionadas à religião, têm a função de preservar costumes e práticas do passado na sociedade, o que gera uma espécie de dominação ideológica, uma forma de controle social (WEBER,1996).

A Semana Mariana Juvenal de Carvalho, objeto deste estudo, foi aqui tratada como um rito de caráter religioso, que enseja a sustentação do mito de que Maria, mãe de Jesus, é uma virgem imaculada abençoada por Deus, que deve ser o exemplo feminino a ser seguido, por exprimir a abdicação de si própria, como ser humano, e de seus desejos, para o serviço sagrado. Nessa percepção, estuda-se uma tradição inventada, realizada todos os anos até os dias atuais, no mês de maio, período do calendário escolar do Colégio Juvenal de Carvalho que é destinado ao culto à Nossa Senhora Auxiliadora.

\footnotetext{
${ }^{1}$ Figuras de liderança da Igreja Católica, como sacerdotes, clérigos, eclesiais e padres, que representam a ligação da humanidade com seres divinos e possuem atuação masculina associada ao controle de seu povo (GEBARA, 2000).

${ }^{2}$ Desfile realizado quando a moça completa 15 anos, como forma de apresentá-la à sociedade.
} 
Importa destacar que esse rito teve seu início na Europa, trazido ao Brasil por Dom Bosco - sacerdote, fundador da ordem Salesiana 3 e criador de uma pedagogia voltada para a educação de jovens das periferias de Turim - que durante toda a sua vida sacerdotal asseverou possuir uma conexão espiritual com Nossa Senhora. Inicialmente, sua devoção foi por Nossa Senhora das Dores (ou da Consolação), em seguida por Imaculada Conceição e, por último, por Nossa Senhora Auxiliadora, sendo esta a figura principal que impulsionou um símbolo de referência feminina a servir de exemplo formativo nas instituições salesianas.

A ordem salesiana, pretendendo ampliar sua atuação pelo mundo e abrir instituições para a formação juvenil, nomeia em 1872 o padre Luís Lasagna para a implantação da obra no Brasil. Em 1883, os salesianos chegaram no estado do Rio de Janeiro e atuaram diretamente no contexto político de transição imperial para o período republicano, a favor dos bispos renovadores, fortalecendo o catolicismo nacional. $O$ grupo de irmãs salesianas chegou ao Ceará no ano de 1933, e no ano seguinte empreenderam a fundação do Colégio Juvenal de Carvalho, onde se realizava a Semana Mariana (ALMEIDA, 2013).

O rito de cultuar Nossa Senhora era uma forma de aperfeiçoar e enobrecer as expressões, ações e desejos da Igreja Católica na manutenção do modelo patriarcal de família e sociedade. Endossada como força cultural, vivida como prática entre os que nele acreditam, o ritual, pleno de significações, servia de sustentáculo para a manutenção de uma tradição sexista que veiculava pensamentos e práticas que reforçavam o lugar da mulher na sociedade.

\section{Percurso teórico-metodológico da investigação}

A escrita historiográfica passou por modificações decorrentes dos fenômenos sociais e políticos que influenciaram a constituição do conhecimento científico (XAVIER; FIALHO; VASCONCELOS, 2018). O movimento de historiadores franceses, juntamente com a criação da revista científica dos Annales, configurou, ao final do século XIX, um marco de renovação para a historiografia (BURKE, 1991). Embora não tenha conseguido romper

\footnotetext{
3 Os seguidores de São Francisco Sales, salesianos, atuaram/atuam no desenvolvimento de projetos voltados para a juventude em paróquias, colégios, universidades, oratórios, dentre outros movimentos juvenis.
} 
completamente a escrita tradicional da história, contribuiu com a ampliação de novas abordagens, fontes, metodologias e interesses de estudo para esse campo (CARDOSO; VAINFAS, 1997).

A História Cultural, a partir da década de 1970, impulsiona a possibilidade de revisitar conceitos, problemas e temáticas e, consecutivamente, amplia a compreensão de fontes históricas, ultrapassando o uso exclusivo de documentos oficiais e valorizando todos os vestígios humanos no tempo que contam sua história (FIALHO; SANTOS; FREIRE, 2020). De acordo com Barros (2011), essa nova compreensão da forma de fazer história alcança também a interdisciplinaridade, ao se utilizar de outros campos de conhecimento e, inclusive, possibilitando o estudo da história na interface com a educação, conforme o presente artigo propõe-se.

Situado no campo da História Cultural, este estudo utilizou a história oral temática como metodologia de pesquisa (MEIHY; HOLANDA, 2007), pois, como ressalta Fialho, Santos e Sales (2019), estudos que partem de um projeto em história oral cientificamente elaborado valorizam as fontes orais como suporte para a elaboração das discussões voltadas para a formação feminina são importantes para a história da educação, afinal, foram as mulheres as principais protagonistas nessa seara, ainda que pouco valorizadas historicamente.

O lócus de pesquisa foi o Colégio Juvenal de Carvalho, selecionado por ser uma instituição confessional inaugurada em 1933, na cidade de Fortaleza, com a proposta de manter a tradição secular da ordem salesiana em educar meninas e moças à luz de Maria. Essa instituição, ofertava ensino secundário primário e secundário de referência para as famílias mais favorecidas economicamente, especialmente as moças que integravam o quadro de alunas internas nos primeiros anos de funcionamento da instituição (ALMEIDA, 2013).

A realização da pesquisa sobre os mitos e os ritos da Semana Mariana foi autorizada junto à direção do Colégio Juvenal de Carvalho, que indicou os dois entrevistados com a justificativa plausível de que eram os principais protagonistas na organização desse evento na década de 1990, inclusive, a diretora pedagógica intermediou o primeiro contato. Neste, realizou-se o convite, a leitura e assinatura do Termo de Consentimento Livre e Esclarecido; após se esclarecer sobre o objetivo da 
pesquisa, a forma de participação, a ausência de benefícios, a possibilidade de desistência a qualquer momento, a preservação do anonimato etc.

Entrevistou-se, no Colégio Juvenal de Carvalho, primeiramente, a irmã salesiana que finalizou seus estudos no colégio e em seguida entrou para a Congregação Salesiana, atuando como professora na referida instituição. Essa religiosa não apenas participou da organização da Semana Mariana durante a década de 1990, mas ainda trabalhava no colégio, o que facilitou o contato. Em seguida, entrevistou-se o coordenador do "Mês Mariano", que participou como organizador deste evento no referido recorte temporal; ele ainda prestava serviços no colégio. Para assegurar a preservação da identidade dos colaboradores, foram utilizadas apenas as nomenclaturas "coordenador" e "irmã salesiana".

As duas entrevistas em história oral temática trataram, especificamente, sobre a Semana Mariana (mês mariano), bem como sua finalidade, princípios e a relação com a educação feminina. As narrativas tiveram duração de aproximadamente 30 minutos cada, consoante ao agendamento prévio realizado de acordo com a disponibilidade dos entrevistados: dia 8 de abril de 2015, com o coordenador da Semana Mariana; e dia 22 de abril de 2015, com a irmã salesiana. Elas foram gravadas por meio de equipamento digital, transcritas na íntegra e textualizadas, transformando-se na principal fonte para o estudo sobre a Semana Mariana do Colégio Juvenal de Carvalho.

\section{Semana Mariana do Colégio Juvenal de Carvalho: educação feminina e valores marianos}

De acordo com o site missaosalesiana.org.br, que conta a história de Maria Auxiliadora, compreende-se a explicação para a escolha dessa personagem como pilar da função educativa na ordem salesiana. A Igreja Católica nomeou Maria com o título de Nossa Senhora Auxiliadora em 1571, após um confronto entre cristãos e mulçumanos.

O Império Otomano, que ocupava espaço de privilégio, mantinha conflitos com a Europa e a Ásia, por isso importa considerar que este império "tem uma história bastante específica, que se desenvolve no entroncamento de contextos geográficos e culturais maiores, entre a Cristandade e o Islã" (SANTOS, 2018, p. 6). A Igreja Católica sentia-se 
ameaçada e, recorrendo ao apoio do Papa Pio V e de Dom João da Áustria, somaram forças (junto aos protestantes da região) contra os otomanos, iniciando uma batalha naval (SANTOS, 2018).

A narrativa do site missaosalesiana.org.br aponta que os soldados cristãos, já temendo a derrota, surpreenderam-se ao ver os otomanos em retirada após perderem 224 navios, sendo mais de noventa destes afundados ou incendiados. Posteriormente, os otomanos presos confessaram ter visto uma senhora no céu durante a batalha, e que ela causou pavor. Como os cristãos em confronto não pararam de rezar o Rosário ${ }^{4}$ e as igrejas fizeram procissões, jejuns e oração pela causa da guerra, o Papa Pio V introduziu a invocação ao auxílio dos cristãos e o título de Nossa Senhora Auxiliadora ou Maria Auxiliadora, que segundo acreditam, foi a responsável pela vitória dos cristãos no referido confronto (CAMPOS, 2018).

A partir de 1862 a devoção à Maria Auxiliadora popularizou-se, com os esforços de Dom Bosco e de Madre Mazarello5; o primeiro dedicava-se a instruir e instrumentar profissionalmente jovens do sexo masculino, e a última centrava ênfase na educação e profissionalização feminina a partir da criação do Instituto das Filhas de Maria Auxiliadora. Articulados, conseguiram atuar nos cinco continentes do mundo.

Dom Bosco mandou pintar um quadro de Nossa Senhora Auxiliadora (), de acordo com um sonho com a Auxiliadora dos Cristãos: segurando o filho no colo, que representaria toda a humanidade; com pés descalços, que significa caminhada e humildade; e a coroa na cabeça que faz alusão à autoridade de mãe. O resultado dessa pintura ficou popularmente conhecida como a imagem a seguir:

\footnotetext{
${ }^{4}$ Rosário é uma prática religiosa católica que consiste na reza do objeto denominado terço, que possui um conjunto de contas correspondentes a quinze dezenas de "ave-marias" e quinze "padre-nossos", em alusão à devoção mariana.

${ }^{5}$ Maria Domingas Mazzarello nasceu no ano de 1837, no norte da Itália, trabalhou no campo com sua família e em seguida com costura, objetivando ensinar um ofício às jovens da cidade onde morava. A oficina de costura transformou-se num local para a convivência de jovens e de devoção à Nossa Senhora (Fonte: MADRE MAZARELLO. Disponível em: http://www.mazzarello.com.br/historia/madre-mazzarello/).
} 


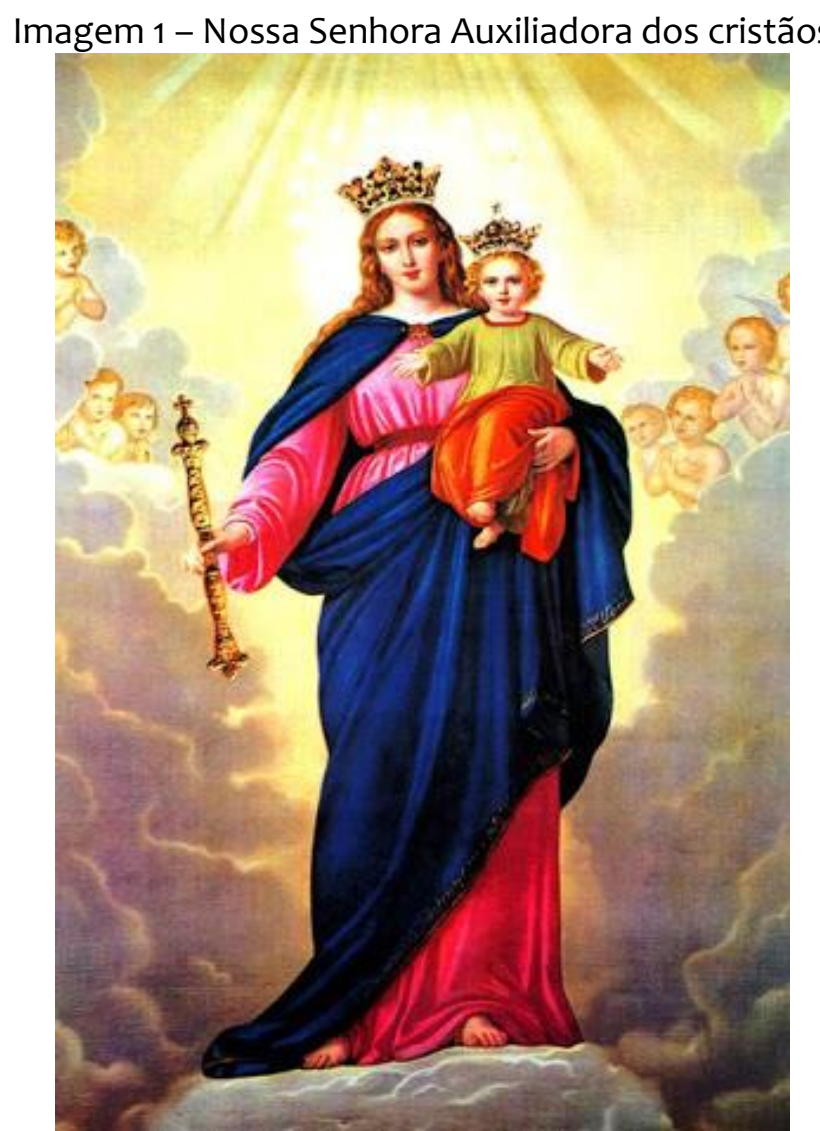

Fonte: https://nossasenhoradetodasasfaces.blogspot.com/ 2018.

Dom Bosco, como fundador da Ordem Salesiana, escolheu o dia 24 de maio como data de referência para os festejos em toda a comunidade salesiana desse mito, reforçado com celebrações em devoção à Nossa Senhora Auxiliadora nas escolas salesianas do mundo inteiro. No Colégio Juvenal de Carvalho, em Fortaleza, lócus desse estudo, não foi diferente, pois desde o ano de sua fundação (1933) essa tradição é celebrada e o rito endossado.

O ritual inicia-se com uma preparação de nove dias (a novena), por meio de orações e reflexões exaltando a figura de Nossa Senhora; as estudantes deveriam exercitar a oração como forma de crescimento espiritual.

O novenário era dessa maneira: uma oração eucarística onde a pessoa que era encarregada daquele dia entrava em contato com o sacerdote e ele sugeria um tema que dava margem e incentivava a devoção e de tudo aquilo que era importante da vida de Nossa Senhora. É colocar Nossa Senhora no mistério eucarístico. E por quê? Porque Jesus é filho de Maria. [...] elas traziam uma imagem para a sala e prestavam sua homenagem na classe. Todos os dias tinha uma homenagem especial e 
também o colégio inteiro rezava o terço, determinadas classes rezavam um mistério ${ }^{6}$. O mistério dependia do dia da semana. E depois tinha um momento especial daquela turma na capela, que tinha a oferta das flores, simbolizando o quê? Tudo de bom que a jovem tinha para oferecer a Nossa Senhora, era a bondade, era a amizade, era a gratidão, era o amor, era a compreensão, quer dizer... eram virtudes especiais que herdavam de Nossa Senhora. (IRMÃ SALESIANA, 22 abr. 2015)

Percebe-se, a partir da narrativa, que a simbologia mariana incutia diariamente na moça/estudante salesiana a importância de imitar e cultivar a perfeição de Nossa Senhora, esta alcançada por intermédio da oração, devoção à Maria e da adoção de comportamento consoante à vida recatada e pura, sendo: bondosas, amigas, gratas, amorosas e compreensivas. Para o desenvolvimento moral não se discutiam os problemas sociais e educacionais da década de 1990, e a educação era alheia às questões políticas (LIMA; SANTOS, 2018). O foco educacional não era contornar os múltiplos fatores que permeavam o fracasso escolar (PEREIRA; RIBEIRO, 2017), tampouco discutir as políticas de investimento educacional (FLORENCIO; FIALHO; ALMEIDA, 2017) ou de formação de professores (JARDILINO; SAMPAIO, 2019), ainda que houvesse muitas professoras leigas e a escola normal fosse um espaço restrito para a formação docente, profissão majoritariamente feminina por ser entendida como extensão do lar (FREITAS, 2020).

O aspecto da maternidade e subserviência à figura masculina também era exaltado como uma missão da mulher (LOURO, 2004), para isso trabalhava-se com a reflexão a partir dos Evangelhos da Bíblia na Semana Mariana:

Maria, nas bodas de Caná (Evangelho de S. João 2; 1-11), o que foi que ela fez? Ela foi convidada para um casamento, ela e Jesus diante da dificuldade que era a falta de vinho, o que foi que ela fez... o que foi que ela disse: "Fazei tudo o que ele vos disser". Então ela não passou por cima do filho, que era superior a ela, que é o Salvador do mundo. [...] vemos aí a abertura de Maria e ao mesmo tempo a obediência frente ao seu filho que é o Salvador. (IRMÃ SALESIANA, 22 abr. 2015) ${ }^{8}$

\footnotetext{
6 O terço possui 4 mistérios, contemplados antes de iniciar um "padre-nosso" e dez "ave-marias". Os mistérios podem ser Gloriosos, Gozosos (da alegria), Luminosos e Dolorosos e cada um deles representa os momentos da vida de Maria e de Jesus dos quais os fiéis precisam apropriar-se, assimilando os sacrifícios e as bem-aventuranças vivenciados pelas figuras sagradas que devem ser imitados na prática cristã.

7 Informação fornecida por Irmã Salesiana, em 22 de abril de 2015, na cidade de Fortaleza.

8 Informação fornecida por Irmã Salesiana, em 22 de abril de 2015, na cidade de Fortaleza.
} 
O trabalho de educação feminina realizado durante a novena buscava unir o humanismo e a religiosidade para formar moças castas, católicas fervorosas, esposas e filhas prendadas, subservientes e mães dedicadas. Inclusive, durante os primeiros anos de funcionamento do Colégio Juvenal de Carvalho, a Semana Mariana era a principal atividade, pois a novena dividia-se em oração do terço, missa e reflexão bíblica, com o intuito de incutir boas práticas de devoção. Findado os dias da novena, iniciava-se o mês de maio, aquele destinado a comemorar o mês das mães, em especial, da mãe de todas as mães: Nossa Senhora.

O mês de maio a gente deixava assim especificamente para estudar e fundamentar as virtudes de Nossa Senhora, a bondade, o serviço, a disponibilidade. [...] também são estudados temas bíblicos, como Maria na Igreja, qual o papel de Maria? É uma mãe medianeira, então são virtudes especiais de Nossa Senhora que são vistas nesse período. (IRMÃ SALESIANA, 22 abr. 2015) ${ }^{9}$

O mês mariano, ao conservar a tradição de celebrar as virtudes de Nossa Senhora Auxiliadora, educava as moças para seguir seu exemplo por meio do alinhamento de práticas pedagógicas voltadas para essa tarefa.

Hoje se faz todos os Bom-Dia, que são em torno de Nossa Senhora e um tema também que se desenvolve em sala, vamos supor que hoje eu pegue Nossa Senhora como medianeira, no outro dia pegue Nossa Senhora como aquela que é cheia de misericórdia, de bondade... então vai variar de acordo com o Bom-Dia que é dado no som pelas manhãs. Agora, independentemente disso, para todo mundo, as turmas vão à capela fazer sua homenagem, porque como são muitas turmas, cada turma vai à capela e faz, com seu catequista ou sua catequista, uma homenagem, que pode ser uma celebração da palavra preparada pelo professor com a turma, ou então pode ser uma celebração da eucaristia [...] (COORDENADOR, 08 abr. 2015) $)^{10}$

O culto e a veneração à figura de Maria, com a prática da imitação, ensejavam a perpetuação da pureza, e até mesmo a iniciativa de remissão dos pecados. Por intermédio dessa mãe que era considerada "misericordiosa" e "intercessora", cabia às estudantes que não se encaixavam no perfil “mariano de ser” recorrer à absolvição divina

\footnotetext{
9 Informação fornecida por Irmã Salesiana, em 22 de abril de 2015, na cidade de Fortaleza.

10 Informação fornecida pelo Coordenador da Semana Mariana, em 08 de abril de 2015, na cidade de Fortaleza.
} 
por meio de homenagens e repetição de orações, para realinhar seu modo de ser e portar-se perante a sociedade. Ressalta-se também a constante vigilância dos comportamentos femininos, por parte dos olhos sagrados da Virgem e da diligência dos pais e das educadoras, para que as regras sociais e morais não fossem infringidas (MAGALHÃES JUNIOR, 2003).

Além de orações e reflexões sobre Nossa Senhora, o Colégio aproveitava o momento de festividade que o mês proporcionava para desenvolver os aspectos artísticos e culturais das alunas. A abertura do mês de maio é realizada a partir de dança, apresentação musical ou teatro, preservando os ideais de Dom Bosco em atrair e envolver o público juvenil, de modo a comunicar o que será trabalhado ao longo do mês: "Primeiro nós fazemos uma abertura para conscientizar aquilo que a gente quer imitar, vivenciar... e o porquê disso (COORDENADOR, 08 abr. 2015) ${ }^{11}$. Nota-se que o objetivo de imitação ao modelo divino conserva-se para fins de adestramento e disciplinamento dos corpos.

Cada vivência, reflexão e atividades ao longo do mês preparavam as estudantes salesianas para o rito de 24 de maio, que era esperado por gestores, funcionários, alunas, professores, pais e colaboradores.

Nesse dia não existe função de trabalho na escola, como os escritórios e repartições burocráticas, pois todos estão envolvidos nesta celebração. Todos os alunos da noite, da tarde e da manhã se encontram as $8 \mathrm{~h}$ para a grande missa, que é o 24 de maio, onde cada expressão da escola, cada nível, seja Infantil, Fundamental ou Ensino Médio, têm uma participação específica nessa celebração. Cada um assume uma parte da celebração e nesse sentido de cada um assumir uma parte existe um significado de celebrar melhor aquilo que foi a síntese do que viveu naquele mês. Para os maiores, nós já fazemos um ato solene de coroação de Nossa Senhora, que têm mais um sentido de dizer, de dar importância à essa companheira de caminhada que a gente elege na vida. E para essa companheira de caminhada a gente diz - olha, se Deus reconheceu Maria com sua importância, nós também devemos reconhecer qual o sentido e qual o lugar que ela deve ocupar nas nossas vidas. (COORDENADOR, 08 abr. 2015) 12

\footnotetext{
${ }^{11}$ Informação fornecida pelo Coordenador da Semana Mariana, em 08 de abril de 2015, na cidade de Fortaleza.

12 Informação fornecida pelo Coordenador da Semana Mariana, em 08 de abril de 2015, na cidade de Fortaleza.
} 
Entendemos, a partir da narrativa acima, que o rito mariano não diz respeito simplesmente a uma devoção, já que ele era vivenciado corriqueiramente por meio de reflexões, atividades e celebrações. A crença nos mitos e a conservação dos ritos pela instituição são evidenciadas tanto no imaginário social, como nas práticas educativas cotidianas. Afinal, “Não é só rezar o terço, não é só rezar Ave-maria ou Salve-Rainha, é, sobretudo, por em prática na sociedade as virtudes que são tão importantes hoje: o amor, a obediência, o perdão, a justiça, né?" (IRMÃ SALESIANA, 22 abr. 2015)².

O rito em questão ocupa lugar no imaginário de cada participante da comunidade salesiana e mantém evidente o mito do modelo mariano de ser, bem como a crença de que é possível receber auxílio de Nossa Senhora, que intercede pelos cristãos. Percebe-se que ainda na década de 1990 eram valorizados os princípios da oração, da escuta e da obediência na escola, responsabilidade que recaia sobre as mulheres com maior ênfase, pois deveriam comportar-se e agir como Maria, ou seja, como uma santa. Segundo Dinarte e Corazza (2019) importa constituir um espaço poético como tradução didática para fomentar uma educação mais sensível e humana, no entanto, voltada para a criticidade e não para a alienação do educando. Inclusive, Vasconcelos, Fialho e Lopes (2018) chamam atenção para a necessidade de uma educação libertadora não centrada na disciplina.

O mito da virgem e santa Maria que intercede pelos humanos na terra, apoiado nos ritos da Igreja Católica e de colégios com esse viés religioso, perpassam a história brasileira influenciando a educação de pobres e ricos (ANANIAS; SANTOS, 2020). Inclusive, perpassando a década de 1990 e permanecendo até no século XXI, todavia, com algumas alterações e flexibilizações decorrentes das transformações da sociedade pósmoderna.

Barthes (2001) descreve que o mito, antes de qualquer coisa, é uma fala e precisa de condições especiais para sua constituição. No caso do culto a Maria, essa fala era propagada e endossada na tradição cristã pela Igreja, pela família e pela instituição educacional. Desse modo, constituiu-se o mito de comportamento feminino ideal a ser seguido em torno da mulher, pois esta deveria representar a humildade, a maternidade e a subserviência; e os ritos eram elaborados para cultivar esse mito.

\footnotetext{
13 Informação fornecida por Irmã Salesiana, em 22 de abril de 2015, na cidade de Fortaleza.
} 
Ao contrário da figura exemplar de Maria, há Eva, mulher que ilustra um comportamento abominável, pois está associada ao pecado, à transgressão e à manipulação feminina que leva o homem ao erro. Essas duas figuras contraditórias são utilizadas pela religião católica, por meio de mitos, para exercerem um papel de adestramento dos corpos e dos comportamentos femininos (DEL PRIORE, 2000). Para alcançar a salvação prometida pelo discurso religioso, as moças de elite deveriam fugir da marca do pecado instituído por Eva e, com toda a sujeição, gerar e criar bons filhos para a manutenção do projeto de dominação e controle da igreja e das elites sobre as classes subalternas na sociedade. Dessa maneira, importa refletir criticamente a quem interessava esse tipo de educação, bem como seu propósito, afinal, ela buscava manter um status quo vigente, que atendia aos interesses dominantes, ou seja, das famílias com mais posses.

Como mito entende-se uma narrativa tradicional acerca de fatos e acontecimentos que ganharam lugar na origem dos tempos, com o propósito de fundar a ação ritual dos sujeitos dos dias de hoje e, de modo geral, a instruir as formas de ação e de pensar por meio das quais o indivíduo compreende a si próprio no mundo que lhe cerca, logo, importa refletir sobre eles. As escolas católicas, seguindo os princípios instituídos pela Igreja, reproduzem as narrativas de modelo feminino utilizando a bíblia como recurso didático e constituem seus mitos e ritos com o intuito de instrução e preservação de costumes que não são desprovidos de intencionalidade. Ao preservar o culto à Maria, mulher pura que ao receber uma mensagem do anjo foi obediente e, por isso, encontrou graça diante de Deus (Lucas 1, 30), reforça-se que Eva, por não ter seguido o mesmo ato de obediência, deixando-se persuadir pela serpente, recebe sua sentença: "Porei inimizades entre ti e a mulher, entre a tua descendência e a dela. Esta te ferirá a cabeça e tu tentarás ferir teu calcanhar" (Gêneses 3, 15).

Assim, a educação católica elegeu o modelo de Maria como padrão ideal a ser ensinado e aprendido e esse perfil ideal de mulher tolheu parte da capacidade reflexiva e criativa feminina, relegando-a ao espaço doméstico por muitos anos, sem o direito de contestação. Segundo Azzi (2008), esse padrão influenciou a formação cultural da sociedade cearense, majoritariamente cristã, com padrões moralizantes, que endossaram o machismo. Para a manutenção e perpetuação dessa crença religiosa, tem-se a 
existência de ritos e rituais, que servem para significar os mitos, afinal, "[...] o rito é a práxis do mito" (GUILOUSKI; COSTA, 2012, p. 91).

Bourdieu (2008, p. 103) afirma ainda que "o rito tem a função social de separar aqueles que se identificam dos que se estranham", mas isso somente é possível por existirem realidades distintas que coexistem num mesmo espaço. Assim, a sociedade forma grandes grupos de seguidores aos mais diversos tipos de ritos, o que torna relevante a "[...] análise de ação ritual como constitutiva dos processos sociais" (LANGDON, 2007, p. 06). Inclusive, Peirano (2001, p. 2) salienta que os rituais são "tipos especiais de eventos, mais formalizados e estereotipados e, portanto, mais suscetíveis à análise porque já recortados em termos nativos", contribuindo para manter e renovar os valores culturais dos sujeitos envolvidos.

Dessa forma, a Semana Mariana ficou evidente como um rito que faz parte da dinâmica de um grupo social, conforme a sua cultura, a religião e os fenômenos diversos asseveram a ideia de continuidade do mito da mulher ideal à projeção de Maria. Dessa maneira, os ritos, “[...] permanecem como mecanismos centrais na construção das diversas sociedades e de suas diferentes formas de organização" (BUTTELLI, 2008, p. 132), todavia, no caso estudado, importa refletir ritos e mito com racionalidade e criticidade para que eles não perpetuem a submissão das mulheres às vontades de poder de determinados grupos.

O mito da mulher ideal - obediente, subserviente ao homem, amorosa, dedicada ao casamento e à criação dos filhos, boa dona de casa, discreta, paciente, recatada etc. era e ainda continua sendo atualizado diariamente no Colégio Juvenal de Carvalho, e, em especial, na Semana Mariana. Afinal, compreende-se que “o ritual é, portanto, a práxis, a ação e a comemoração do mito. O mito é revivido e atualizado mediante a vivência ritualística" (GUILOUSKI; COSTA, 2012, p. 03). Como um depende do outro para continuar em evidência, somente a reflexão crítica, à luz da cientificidade, é capaz de destituir amarras constituídas historicamente, especificamente, quando se trata de crenças religiosas que transmitem um padrão de mulher questionável.

O rito para continuar vivo possui as suas regras embasadas nas ações passadas e exemplificadas no cotidiano de forma a conquistar seus seguidores e convencê-los a continuarem com sua prática; em consonância, a Semana Mariana do Colégio Juvenal de 
Carvalho cultivava nas alunas a necessidade da oração e da fé cristã, instituindo normas de conduta e inculcando valores cristãos que não apenas determinavam o comportamento social da mulher, mas determinava a aceitação do lugar da mulher na sociedade. Ou seja, disseminava-se, por meio da Semana Mariana, a ideia de uma lei soberana e inquestionável de que a mulher precisava ser casta, dócil, mãe e serva, como a própria Mãe de Jesus, condição essencial para a purificação e a salvação. Eram preceitos defendidos pelas escolas católicas, bem como pelo Estado que pregava a normatização social (LOURO, 2004).

As sociedades, de modo geral, perpetuaram seus mitos devido à busca por verdade, sentido e significação ao longo dos tempos. É necessário, todavia, problematizar os mitos e os ritos para que estes não sirvam de alienação. Ao contrário, torna-se factível que o misterioso seja compreendido e que o ser humano descubra a si mesmo como sujeito transformador.

\section{Considerações finais}

Essa pesquisa partiu de uma inquietação inicial que dizia respeito à maneira como a Semana Mariana, realizada no Colégio Juvenal de Carvalho, era utilizada para a preservação de mito e ritos que asseveravam padrões sociais e culturais que condicionaram a mulher à subserviência na sociedade fortalezense no início dos anos de 1990. Para responder a esse problema visitou-se inicialmente o conceito de mito e rito, afinal, considerou-se a Semana Mariana um ritual que, ao exaltar Maria Auxiliadora como modelo feminino de maneira atemporal, endossava o mito de uma mulher ideal amparado em padrões de normalização social.

Com o objetivo de compreender como o mito da mulher virtuosa, à luz do exemplo de Maria, transformava-se em rito na Semana Mariana do Colégio Juvenal de Carvalho - para fomentar a educação feminina voltada para a preservação de valores morais que mantinham a mulher na esfera privada a serviço da família e do lar - foi desenvolvida uma pesquisa científica que analisou, a partir da oralidade de professores envolvidos na sua organização, como se constituía esse ritual. 
Constatou-se que a devoção à Maria Auxiliadora tornou-se mais enfática após a guerra dos otomanos com os cristãos no século XVI, quando estes atribuíram a responsabilidade pela sua vitória à referida Santa. Dom Bosco, principal entusiasta de Maria, fundou a Ordem Salesiana em 1859, uma congregação da Igreja Católica que foi aprovada em 1874, e colaborou para popularizar o culto a Maria.

A Congregação Salesiana expandiu-se mundo afora e chegou a Fortaleza em 1933, implantando o Colégio Juvenal de Carvalho, referência na cidade para a educação das moças da elite. Como a instituição era confessional católica, percebeu-se que os ritos e os mitos inter-relacionavam Religião e Educação, logo, não era possível haver uma dissociação entre esses dois campos. Práticas e ações pedagógicas desenvolvidas no colégio direcionavam as alunas à interiorização dos mitos salesianos, a exemplo da santificação de Maria, da sua devoção e do culto ao modelo comportamental por ela adotado.

O pressuposto levantado inicialmente foi confirmado visto que a educação mariana, fomentada no Colégio Juvenal da Carvalho, endossada na Semana Mariana, propagava padrões socioculturais machistas que condicionavam a mulher à subordinação ao homem, ao asseverar a preservação de padrões comportamentais consoantes ao arquétipo da pureza, paciência e subserviência, que destinavam a mulher aos afazeres de dona de casa prendada, mãe amorosa e esposa dedicada. Uma análise crítica desses resultados permite inferir que a propagação dos valores marianos, nos moldes como eram desenvolvidos, não colaboravam para a emancipação feminina, ao contrário, reforçavam a naturalização do lugar da mulher na sociedade destinado à obediência aos homens - pai e marido -, e às atividades do lar.

A novena, as missas, a eucaristia, as homenagens, o estudo de temas bíblicos e tantas outras atividades pedagógicas empreendidas levavam as alunas a acreditar que Maria não apenas era uma santa a quem deveriam devoção, mas o exemplo de mulher ideal a ser seguido. De tal modo, as moças deveriam agir tal como Maria, e esse modelo de comportamento era extraído de passagens bíblicas, de maneira literal, analisando as atitudes da santa de maneira anacrônica e descontextualizada. Isso permitia, com apoio da sociedade patriarcal e da Igreja Católica, manter a mulher na sua condição de subserviência, pois a obediência inconteste, a paciência, a servidão, a fé, e a dedicação à 
constituição e preservação da família, eram as principais características que moldavam o perfil ideal de mulher. Essa educação, todavia, além de limitar a atuação das mulheres nos espaços públicos de maneira ativa, ao formá-las para serem recatadas, acabava por endossar a ideia de mulher da classe dominante, não apropriada para tantas outras meninas que sequer tinham acesso à escola e às condições materiais e culturais para abdicar do trabalho doméstico e galgar alfabetização.

O Colégio Juvenal de Carvalho consolidou o mito mariano ao longo dos anos e o rito da Semana Mariana corroborou na constituição e, consequentemente, na internalização de verdades inquestionáveis que nortearam o trabalho pedagógico e espiritual das irmãs salesianas e a educação das moças mais abastadas economicamente da cidade de Fortaleza. A aliança existente entre as elites locais e o clero católico conservou os interesses recíprocos dessas instituições dirigentes em preservar o modelo mariano de ser mulher no seio da sociedade. Inclusive, interessa salientar que, ainda em funcionamento, a instituição preserva o mesmo ritual há mais de 86 anos, todos os meses de maio, endossando uma cultura que não colabora com os ideais feministas pósmodernos.

Importa ressaltar que a pesquisa, por sua perspectiva micro-histórica, não é passível de generalizações, ainda que sinalize um padrão de educação feminina perpetuado por séculos na história da educação brasileira, levando as mulheres a uma formação específica voltada para a imitação de padrões rígidos e silenciamentos. Com efeito, torna factível desenvolver reflexões críticas acerca de mecanismos de disciplinamento que são retroalimentados por várias gerações, consoante aos interesses de grupos específicos - a exemplo do católico e da elite - que dificultam o empoderamento feminino e a igualdade de condições para as mulheres nas esferas políticas, econômicas, sociais etc. 
ALMEIDA, Gildênia Moura de Araújo. Mulheres beletristas e educadoras: Francisca Clotilde na sociedade cearense - de 1862 a 1935. 2012. 356 f. Tese (Doutorado em Educação) - Programa de Pós-graduação em Educação Brasileira, Universidade Federal do Ceará, Fortaleza, 2012.

ALMEIDA, Núbia Ferreira. O Colégio Salesiano em Juazeiro do Norte e o Projeto Educacional de Padre Cícero. Fortaleza: Edições UFC, 2013.

ANANIAS, Mauriceia; SANTOS, Lays Regina Batista de Macena Martins dos. Quando o homem sabe ler, escrever e contar, pode, por sua própria individualidade, desenvolver se e esclarecer-se: a escolarização de crianças pobres na província da Parahyba do Norte (1855-1866). Educação \& Formação, Fortaleza, v. 4, n. 1, p. 66-80, 2019. Disponível em: https://revistas.uece.br/index.php/redufor/article/view/453. Acesso em: 18 jun. 2020.

AZZI, Riolando. A Igreja Católica na formação da sociedade brasileira. Aparecida: Editora Santuário, 2008.

AZZI, Riolando. Os Salesianos no Brasil à luz da história. São Paulo: Salesiano Dom Bosco, 1982.

BARTHES, Roland. Mitologias. Tradução de Rita Buongermino e Pedro de Sousa. 11. ed. Rio de Janeiro: Bertrand Brasil, 2001.

BARROS, José D’Assunção Barros. A nova história cultural: considerações sobre o seu universo conceitual e seus diálogos com outros campos históricos. Cadernos de História, Belo Horizonte, v. 12, n. 16, p. 38-63, 2011. Disponível em:

http://periodicos.pucminas.br/index.php/cadernoshistoria/article/view/P.2237-

8871.2011v12n16p38. Acesso em: 18 jun. 2020.

BÍBLIA. Português. A Bíblia de Jerusalém. [Nova edição rev. e amp.]. São Paulo: Paulus, 2002.

BORGES, Carlos Nazareno Ferreira. A significatividade das atividades do pátio na educação salesiana. 2000. 98 f. Dissertação (Mestrado em Educação Física) - Programa de Pós-graduação da Universidade Gama Filho, Rio de Janeiro, 2000.

BOURDIEU, Pierre. A economia das trocas simbólicas. São Paulo: Edusp, 2008.

BURKE, Peter. A Revolução Francesa da historiografia: a Escola dos Annales 1929-1989. Tradução Nilo Odália. São Paulo: Editora Universidade Estadual Paulista, 1991.

BUTLER, Judith. Gender trouble: feminism and the subversion of identity. Nova York: Routledge, 1991. 
BUTTELLI, Felipe Gustavo Koch. Ritos e igualdade de gênero: uma análise da potencialidade de construção de (des)igualdade de gênero nos ritos. HORIZONTE -

Revista de Estudos de Teologia e Ciências da Religião, Belo Horizonte, v. 6, n. 12, p. 127143, 2008. Disponível em:

http://periodicos.pucminas.br/index.php/horizonte/article/view/443. Acesso em: 18 jun. 2020.

CAMPOS, José Vicente Ucha. Blog Nossa Senhora de todas as faces. Fotografia de Nossa Senhora Auxiliadora. 30 jan. 2018. Disponível em:

<https://nossasenhoradetodasasfaces.blogspot.com/>. Acesso em: 31 out. 2021.

CARDOSO, Ciro Flamarion; VAINFAS, Ronaldo (org.). Domínios da história: ensaios de teoria e metodologia. 5. ed. Rio de Janeiro: Campus, 1997.

CHAUÍ, Marilena. Convite à filosofia. São Paulo: Ed. Ática, 2003.

DEL PRIORE, Mary. História das mulheres no Brasil. São Paulo: Contexto, 2000.

DINARTE, Luiz Daniel Rodrigues; CORAZZA, Sandra Mara. Espaço poético como tradução didática: Bachelard e a imagem da casa. Educação \& Formação, Fortaleza, v. 1, n. 2, p. 135148, 2016. Disponível em: https://revistas.uece.br/index.php/redufor/article/view/105/87. Acesso em: 10 out. 2019.

ELIADE, Mircea. Mito e realidade. São Paulo: Perspectiva, 1978.

FIALHO, Lia Machado Fiuza; FREIRE, Vitoria Chérida Costa. Educação formativa de uma líder política cearense: Maria Luiza Fontenele (1950-1965). Cadernos de História da Educação, Uberlândia, v. 17, p. 343, 2018. Disponível em:

http://www.seer.ufu.br/index.php/che/article/view/43290. Acesso em: 18 jun. 2020.

FIALHO, Lia Machado Fiuza; SANTOS, Hannah Franklin dos; FREIRE, Vitória Chérida Costa. Biografia da professora Raquel Dias Araújo: um olhar sobre a docência universitária e a militância política. History of Education in Latin America - HistELA, Natal, v. 3, p. 1-14, 2020. Disponível em: https://periodicos.ufrn.br/histela/article/view/20562/12765. Acesso em: 20 jun. 2020.

FIALHO, Lia Machado Fiuza; SANTOS, Francisco Mayane Benvindo dos.; SALES, José Albio Moreira de. Pesquisas biográficas na história da educação. Cadernos de Pesquisa, São Paulo, v. 26, p. 11-29, 2019. Disponível em:

http://www.periodicoseletronicos.ufma.br/index.php/cadernosdepesquisa/article/view/12 743/6898. Acesso em: 18 jun. 2020.

FLORENCIO, Lourdes Rafaella Santos; FIALHO, Lia Machado Fiuza; ALMEIDA, Nadja Rinelle Oliveira de. Política de formação de professores: a ingerência dos organismos internacionais no Brasil a partir da década de 1990. Holos, Natal, v. 5, p. 303-312, 2017. Disponível em: http://www2.ifrn.edu.br/ojs/index.php/HOLOS/article/view/5757. Acesso em: 17 jun. 2020. 
FREITAS, Anamaria Gonçalves Bueno de. A califasia e a formação de professores na escola normal de São Paulo. Educação \& Formação, Fortaleza, v. 4, n. 1, p. 81-64, 2019. Disponível em: https://revistas.uece.br/index.php/redufor/article/view/520. Acesso em: 18 jun. 2020.

GEBARA, Ivone. Rompendo o silencio: uma fenomenologia feminista do mal. Petrópolis: Vozes, 2000.

GUILOUSKI, Borres; COSTA, Diná Raquel D. da. Ritos e rituais. In: JORNADA INTERDISCIPLINAR DE PESQUISA EM TEOLOGIA E HUMANIDADES, 3., 2012, Curitiba.

Anais [...]. Curitiba: PUCPR, p. 91-109. 2012. Tema: Subjetivação Contemporânea e Religiosa. Disponível em: file:///C:/Users/Adm/Downloads/2jointh-7577\%20(5).pdf. Acesso em: 10 out. 2014.

HOBSBAWM, Eric. Nações e nacionalismo desde 1780. [Tradução de Maria Célia Paoli e Anna Maria Quirino]. Rio de Janeiro: Paz e Terra, 1991.

JARDILINO, Jose Rubens Lima; SAMPAIO, Ana Maria Mendes. Desenvolvimento profissional docente: Reflexões sobre política pública de formação de professores.

Educação \& Formação, Fortaleza, v. 4, n. 10, p. 180-194, 2019. Disponível em:

https://revistas.uece.br/index.php/redufor/article/view/848. Acesso em: 02 fev. 2020.

LANGDON, Esther Jean. Rito como conceito para a compreensão de processos sociais.

Revista Antropologia em Primeira Mão. Florianópolis: UFSC: Programa de Pós Graduação em Antropologia Social, 2007. Disponível em: https://apm.ufsc.br/titulos-publicados/20072/. Acesso em: 29 abr. 2016.

LIMA, Juliana dos Santos; SANTOS, Gilberto Lima dos. Valores, educação infantil e desenvolvimento moral: concepções dos professores. Educação \& Formação, Fortaleza, v. 3, n. 8, p. 153-170, 2018. Disponível em:

https://revistas.uece.br/index.php/redufor/article/view/275/203. Acesso em: 10 de out. 2019.

LOPES, Antonio de Pádua Carvalho. Legislação e processos educativos: A constituição da escola primária no Piauí (1845 a 1889). Educação \& Formação, Fortaleza, v. 4, n. 1, p. 5065, 2019. Disponível em: https://revistas.uece.br/index.php/redufor/article/view/866. Acesso em: 17 maio 2020.

LORIGA, Sabina. O pequeno x: da biografia à história. Belo Horizonte: Autêntica, 2011.

LOURO, Guacira Lopes. Mulheres na sala de aula. In: DEL PRIORE, Mary (org.). História das mulheres no Brasil. São Paulo: Contexto, 2004. p. 371-403.

MAGALHÃES JUNIOR, Antonio Germano. Vigilância, transgressão e “punição": memórias de ex-alunas de escolas católicas de formação de educadoras (1964-1969). 2003. $201 \mathrm{f}$. Tese (Doutorado em Educação) - Programa de Pós-Graduação em Educação Brasileira, Universidade Federal do Ceará, Fortaleza, 2003. 
MARTINS FILHO, Antonio; GIRÃO, Raimundo. O Ceará. 3. ed. Fortaleza: Instituto do Ceará, 1966.

MEIHY, José Carlos Sebe Bom; HOLANDA, Fabíola. História oral: como fazer, como pensar. São Paulo: Contexto, 2007.

MINAYO, Maria Cecília de Souza (org.). Pesquisa social: teoria, método e criatividade. 6 ed. Petrópolis: Vozes, 1994.

PEIRANO, Mariza Gomes e Souza. Rituais como estratégia analítica e abordagem etnográfica (em inglês e português.). Prefácio do livro O Dito e o Feito. Brasília: UnB, 2001. 22 p. (Série Antropologia, 305)

PEREIRA, Anderson de Carvalho; RIBEIRO, Carme Sandra de Jesus. A culpabilidade pelo fracasso escolar e a interface com os "problemas de aprendizagem” em discurso.

Educação \& Formação, Fortaleza, v. 2, n. 5, p. 95-110, 2017. Disponível em:

https://revistas.uece.br/index.php/redufor/article/view/138/121. Acesso em: 10 de out. 2019.

PLATÃO. República. [Tradução de Enrico Corvisieri]. Rio de Janeiro: Editora Best Seller, 2002.

RAGO, Margareth. Epistemologia feminista, gênero e história. In: PEDRO, Joana Maria e GROSSI, Miriam Pilar (org.). Masculino, feminino, plural. Florianópolis: Editora Mulheres, 2000.

RIBEIRO, Arilda Ines Miranda. Mulheres Educadas na Colônia. In: LOPES, Eliane Marta Teixeira; FARIA FILHO, Luciano Mendes de; VEIGA, Cynthia Greive (orgs.). 500 Anos de Educação no Brasil. 2. ed. Belo Horizonte: Autêntica, 2000. p. 79-94.

SANTOS, Ana Carolina dos. Percepções sobre o Império Otomano na obra de Arnold J. Toynbee. 2018. 104 f. Dissertação (Mestrado em História) - Faculdade de Filosofia, Letras e Ciências Humanas da Universidade de São Paulo, USP, São Paulo, 2018.

SAVIANI, Dermeval. Política educacional brasileira: limites e perspectivas. Revista de Educação PUC, Campinas, n. 24, p. 7-16, jun. 2008. Disponível em: http://periodicos.puccampinas.edu.br/seer/index.php/reveducacao/article/view/108. Acesso em: 17 jun. 2020.

SCOTT, Ana Silvia. O caleidoscópio dos arranjos familiares. In: PINSKY, Carla Bassanezi (org.). Nova história das mulheres no Brasil. São Paulo: Contexto, 2012. p. 15-42.

TAMANINI, Paulo Augusto. Rito de instituição e práticas religiosas em uma celebração ortodoxa ucraniana. Revista Brasileira de História das Religiões, Maringá, v. 2, n. 6, p. 105118, 2010. Disponível em: http://www.periodicos.uem.br/ojs/index.php/RbhrAnpuh/article/view/30310. Acesso em: 20 jun. 2020. 
VASCONCELOS, José Gerardo; FIALHO, Lia Machado Fiuza; LOPES, Tânia Maria. Educação e liberdade em Rousseau. Educação \& Formação, Fortaleza, v. 3, n. 8, p. 210-223, 2018.

Disponível em: https://revistas.uece.br/index.php/redufor/article/view/278. Acesso em: 02 fev. 2020.

VASCONCELOS, Larissa Meira; FIALHO, Lia Machado Fiuza; MACHADO, Charliton José dos Santos. Facetas da (im)potência viril na Revista Careta: educação e masculinidades no Estado Novo (1937-1945). Acta Scientiarum Education, Maringá, v. 40, p. 1-12, 2018. Disponível em: http://periodicos.uem.br/ojs/index.php/ActaSciEduc/issue/view/1499/showToc. Acesso em: 20 jun. 2020.

WEBER, Max. Sociologia da religião: tipos de relações comunitárias religiosas. Brasília: UnB, 1996.

XAVIER, Antônio Roberto; FIALHO, Lia Machado Fiuza; VASCONCELOS, José Gerardo. História, memória e educação: aspectos conceituais e teórico-metodológicos. Fortaleza: EdUECE, 2018.

Recebido em: 01/08/2020 Revisões requeridas em: 07/06/2021 Aprovado em: 15/06/2021

Universidade do Estado de Santa Catarina - UDESC Programa de Pós-Graduação em Educação - PPGE Revista Linhas Volume 22 - Número 50 - Ano 2021 revistalinhas@gmail.com 